\title{
The Effect of Heat Treatment on Dynamic Properties of an Additively Manufactured Ti-6Al-4V Alloy
}

\author{
Shuangyin Zhang ${ }^{1}$, Yunfei Wang ${ }^{1}$, Tao Suo ${ }^{1,2}$, Jin Yao ${ }^{1}$, Xin Lin ${ }^{3}$, Weidong Huang ${ }^{3}$, Yulong Li ${ }^{2,4}$ \\ and Jianghua Shen $1, * \mathbb{D}$ \\ 1 School of Aeronautics, Northwestern Polytechnical University, Xi'an 710072, China; \\ zsy2010@nwpu.edu.cn (S.Z.); yunfei@mail.nwpu.edu.cn (Y.W.); suotao@nwpu.edu.cn (T.S.); \\ yaojin@mail.nwpu.edu.cn (J.Y.) \\ 2 Shaanxi Key Laboratory of Impact Dynamic and Its Engineering Application, Northwestern Polytechnical \\ University, Xi'an 710072, China; liyulong@nwpu.edu.cn \\ 3 The State Key Laboratory of Solidification Processing, Northwestern Polytechnical University, \\ Xi'an 710072, China; xlin@nwpu.edu.cn (X.L.); huang@nwpu.edu.cn (W.H.) \\ 4 School of Civil Aviation, Northwestern Polytechnical University, Xi'an 710072, China \\ * Correspondence: j.shen@nwpu.edu.cn; Tel.: +86-029-88460969
}

check for

updates

Citation: Zhang, S.; Wang, Y.; Suo, T.; Yao, J.; Lin, X.; Huang, W.; Li, Y.; Shen, J. The Effect of Heat Treatment on Dynamic Properties of an Additively Manufactured Ti-6Al-4V Alloy. Crystals 2021, 11, 111. https:// doi.org/10.3390/cryst11020111

Received: 31 December 2020

Accepted: 23 January 2021

Published: 26 January 2021

Publisher's Note: MDPI stays neutral with regard to jurisdictional claims in published maps and institutional affiliations.

Copyright: (c) 2021 by the authors. Licensee MDPI, Basel, Switzerland. This article is an open access article distributed under the terms and conditions of the Creative Commons Attribution (CC BY) license (https:// creativecommons.org/licenses/by/ $4.0 /)$.

\begin{abstract}
Heat treatment processing is commonly applied for additively manufactured metal materials, since the as-fabricated material frequently exhibits high internal stress and self-cracking. In this work, a heat treatment route was applied to an additively manufactured Ti-6Al-4V alloy, and its effect on the dynamic compressive behavior was investigated. The experimental results showed that the heat treatment process not only increased the dynamic compressive strength of the material, but also induced a change of the dynamic compressive strength from isotropic to anisotropic. In addition, the strain rate sensitivity of the material was reduced by heat treatment, even though both the as-deposited and heat-treated samples demonstrated positive sensitivity to the loading rate. Microstructural analysis suggested that the grain size and morphology were the same before and after heat treatment, while the internal stress increased due to heat treatment.
\end{abstract}

Keywords: laser solid forming (LSF); additive manufacturing; dynamic properties; strain rate sensitivity; anisotropy

\section{Introduction}

Three-dimensional printing is a breakthrough technique and is now widely used to manufacture complex structures that can hardly be produced with traditional techniques. In comparison with traditional technologies, 3D printing or laser deposition additive manufacturing is characterized by high flexibility and short production cycle and is especially suitable for complex-shaped components. Therefore, it has been widely used in many fields including automobile and aerospace industries [1-3]. Due to the rapid cooling and solidification characteristics of laser additive manufacturing, the microstructure of as-deposited samples consists of Widmanstätten $\alpha$ laths and a little acicular columnar prior- $\beta$ grains, which grow epitaxially from the substrate along the deposition direction. The lattice structure is characterized by high strength and low plasticity. In addition, the heat treatment processing is used for additively manufactured (AM) components to advance mechanical properties. The author's previous research results show that $\alpha$ laths precipitate from the original $\beta$ grain boundary after heat treatment and that they coarsen within the grain, which contributes to the improvement of plasticity [4]. Although research on processing-microstructure-properties is widely reported, there are few reports on the dynamic properties of AM alloys, especially on AM alloys after heat treatment processing. Previous studies showed that Ti alloys have a remarkable dependency on loading conditions in terms of the mechanical behavior and failure mode [4-7]. For example, 
an adiabatic shear banding failure mode is more likely to occur under high strain rate loading than under low strain rate loading [6]. It has been revealed that the strain rate dependency is naturally related to deformation mechanisms or further to microstructures. Ahmed et al. [8] reported that the activation of deformation-induced phase transformation and twinning is strongly dependent on strain rate. Deformation twinning especially has long been reported in metals of hexagonal close-packed structures and is found to be strongly strain rate-sensitive [9-11]. Furthermore, it is known from former reports that additively manufactured alloys show quite different microstructures from those processed by traditional technology [12-15], implying that AM alloys may have a different strain rate sensitivity as regards deformation mechanisms, mechanical properties and failure modes. Besides, this issue is very important for structural materials that are intended to be used in high-speed vehicles such as high-speed trains and space shuttles. In the present study, a heat treatment process was applied to an AM Ti-6Al-4V alloy to study its effect on the dynamic behavior and strain rate dependency of the materials.

\section{Materials and Methods}

\subsection{Preparation of Materials}

Commercial Ti-6Al-4V powders with a diameter of $80-120 \mu \mathrm{m}$ were used as initial materials. A block with dimensions of $40 \mathrm{~mm}$ (length) $\times 40 \mathrm{~mm}$ (width) $\times 15 \mathrm{~mm}$ (height) was produced via 3D laser deposition additive manufacturing using an LSF-I laser solid forming system that consists of a $5 \mathrm{~kW}$ ROFIN-SINA 850 continuous wave $\mathrm{CO}_{2}$ laser (Rofin AG, Berzeliusstraße, Hamburg, Germany), a 5-axis numerical control working table, a lateral powder feeder nozzle and an inert gas chamber filled with pure argon with the oxygen content below $50 \mathrm{ppm}$. The detailed processing parameters are shown in Table 1. It is worth mentioning that to reduce moisture, the original powders were dried at a temperature of $393 \mathrm{~K}$ in a vacuum environment for $2 \mathrm{~h}$ before the manufacturing process. A forged pure Ti-6Al-4V plate with dimensions of $110 \times 40 \times 6 \mathrm{~mm}^{3}$ was used as a substrate for the Laser Additive manufacturing (LAM) process, which was grounded with the $\mathrm{SiC}$ paper and then degreased with acetone and ethanol before use. A photograph of the fabricated block is shown in Figure 1a. A solution aging heat treatment process at $950{ }^{\circ} \mathrm{C} \times 1.5 \mathrm{~h} /$ air cooling $+600^{\circ} \mathrm{C} \times 1 \mathrm{~h} /$ air cooling was then applied to the as-deposited sample.
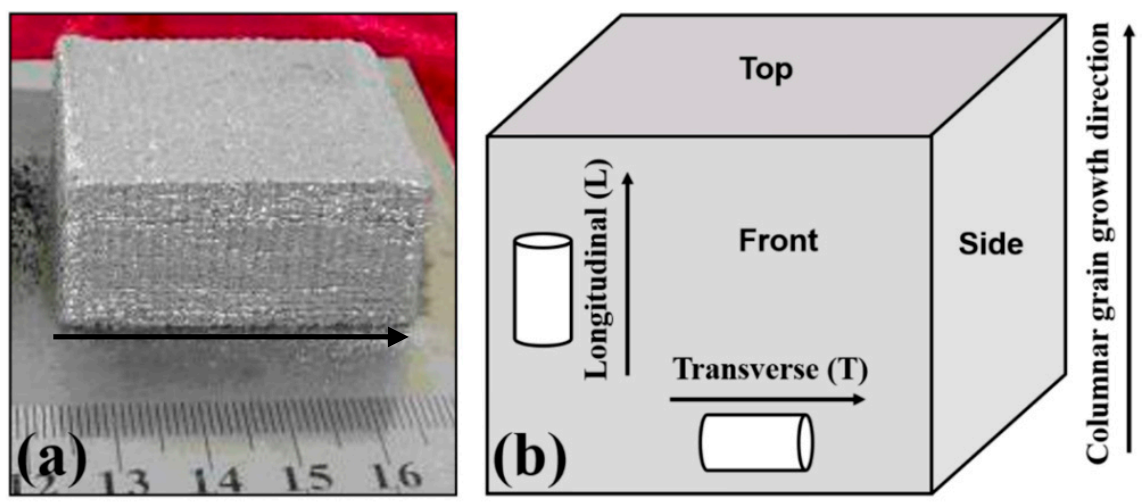

Figure 1. Image (a) demonstrates an as-deposited AM Ti-6Al-4V alloy (the arrow indicates the direction in which the powder feeding nozzle moves), while image (b) illustrates the definition of sample faces and loading directions schematically. 
Table 1. Forming processing parameters.

\begin{tabular}{ccccccc}
\hline $\begin{array}{c}\text { Laser Power } \\
(\mathbf{W})\end{array}$ & $\begin{array}{c}\text { Speed of } \\
\text { Scanning } \\
(\mathbf{m m} / \mathbf{s})\end{array}$ & $\begin{array}{c}\text { Powder } \\
\text { Feeding } \\
(\mathbf{g} / \mathbf{m i n})\end{array}$ & $\begin{array}{c}\text { Shielding Gas } \\
\text { Flow Rate }(\mathrm{L} / \mathbf{h})\end{array}$ & $\begin{array}{c}\text { Spot Diameter } \\
(\mathbf{m m})\end{array}$ & $\begin{array}{c}\text { Overlapping } \\
\mathbf{( \% )}\end{array}$ & $\begin{array}{c}\text { Increment of } \\
\text { the Z-axis } \\
(\mathbf{m m})\end{array}$ \\
\hline 2500 & 5 & 6 & 200 & 3 & 40 \\
\hline
\end{tabular}

\subsection{Microstructure Characterization}

The microstructures of as-deposited samples were characterized along the top, front and side faces using an optical microscope, as shown in Figure 1b, where the sample surfaces were first mechanically polished with Grit 7000 sandpaper and then finished by etching using a solution composed of $2 \mathrm{~mL} \mathrm{HF}, 6 \mathrm{~mL} \mathrm{HNO}_{3}$ and $100 \mathrm{~mL} \mathrm{H}_{2} \mathrm{O}$. Electron backscatter diffractor (EBSD) attached to a scanning electron microscope (SEM, Zeiss Supra55, Carl Zeiss AG, Göschwitzer, Jena, Germany) was also used to examine the microstructures of as-deposited and heat-treated samples. Before EBSD scanning, the specimens were electrochemically polished using a solution of $8 \%$ perchloric acid and $92 \%$ ethanol, at $28 \mathrm{~V}, 40 \mathrm{~s}$ and $20^{\circ} \mathrm{C}$ after mechanical polishing. The EBSD was performed in the following conditions: an acceleration voltage of $20 \mathrm{KV}$ and a step size of $0.5 \mu \mathrm{m}$. The results were processed using the HKL Technologies Channel 5 software.

\subsection{Mechanical Testing}

The dynamic mechanical properties of the samples before and after heat treatment were evaluated on a desktop split-Hopkinson pressure bar (SHPB) (self-made by Shaanxi Key Laboratory of Impact Dynamic and Its Engineering Application, X'an, China) with two strain rates, $500 \mathrm{~s}^{-1}$ and $3000 \mathrm{~s}^{-1}$, under compression loading. The compression tests were performed along both longitudinal $(\mathrm{L})$ and transverse $(\mathrm{T})$ directions, as shown in Figure $1 \mathrm{~b}$. The samples have a cylindrical shape with dimensions of $\varnothing 5 \mathrm{~mm} \times 5 \mathrm{~mm}$. To ensure reproductivity, at least three repetitive tests were performed for each condition.

\section{Results and Discussion}

Figure 2a-c display the optical images of the as-deposited sample along top, side and front faces, while Figure $2 \mathrm{~d}$ presents the microstructure in a 3D view. Figure $3 \mathrm{a}-\mathrm{c}$ display the optical images of the heat-treated sample. Columnar prior-beta grains with an average grain width of $300 \mu \mathrm{m}$ are clearly observed due to epitaxial growth from bottom to top. There is no significant change in the beta grain size after heat treatment. Furthermore, fine needle grains are visible within the columnar grains. The needle grains have been widely reported for additively manufactured Ti-6Al-4V alloys as the $\alpha^{\prime}$ martensite phase [16]. From the optical images, it is easy to understand that the large grains of hundred microns were originally beta-phase grains that grew along the deposition direction. As heat disperses very quickly in metals, the beta-phase grains transferred into alpha needles but maintained their shape. That is why needle grains were observed within the columnar grains. Laser-induced phase transition is the way of laser irradiation, so that the temperature of the phase-change material increases due to the absorption of heat, and phase transition is observed above the phase transition temperature. The laser additive manufacturing process uses a high-energy laser beam as a moving heat source, synchronously melting the metal powder. This microstructure is formed by rapid solidification. In the remelting process, the microstructure of the previous layer is reheated and cooled, the mechanism of microstructure formation is related to the laser-induced phase transition. It is necessary to mention that $\beta$-phase grains are merely observed in the samples before and after heat treatment, as shown in Figure 4a,b. The phase distribution map in Figure 4e,f also shows that most of the observations were beta phases. This result is in accordance with the previous report [16]. In particular, it is visible, for example, in micrographs in Figure $2 b-d$ that some of the grains of eutectoid colonies (appearing grey) are separated from each other by the layers of the phase appearing white. Such behavior of the grain boundary 
phase is intimately connected with the so called complete and incomplete wetting of grain boundaries by the second solid phase. The morphology of the integranular phase strongly influences the overall mechanical properties of a polycrystalline composite [17]. A reason for the difference might be due to the microstructure evolution with grain boundary wetting phase transformation of the $\alpha$ allotriomorph during the $\beta \rightarrow \alpha$ phase transformation in the Ti-6Al-4V alloy during heat treatment (Figure $4 \mathrm{~b}$ ). This will be further studied. By comparing the EBSD images, it can be seen that the grain morphology hardly changes after heat treatment. The conclusion is also supported by the $\alpha$ lath size spread diagram. The results of XRD are also consistent with these results in Figure $5 \mathrm{~b}$. As can be seen from the XRD diffraction spectrum, the volume fraction of alpha phases increased after heat treatment.
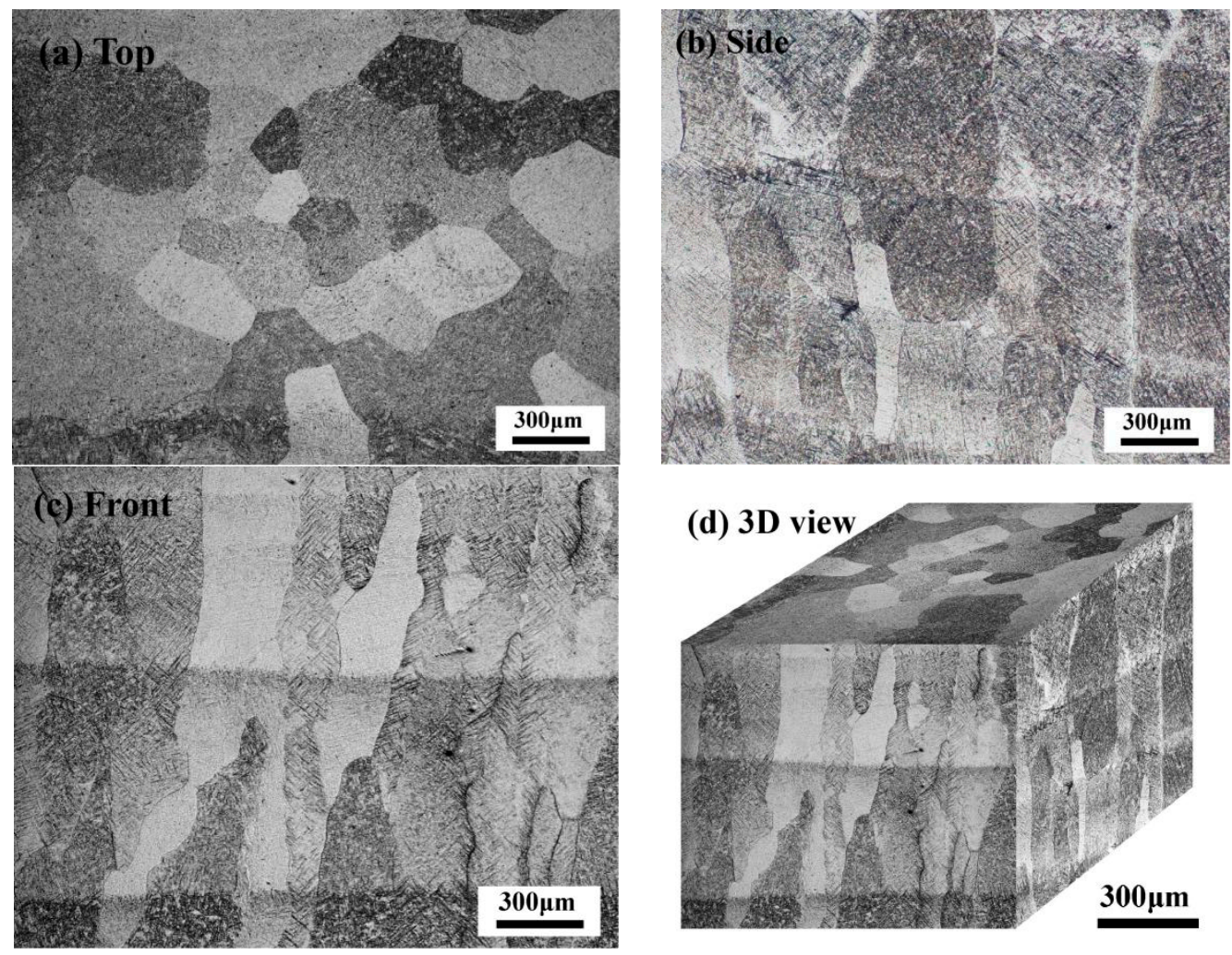

Figure 2. (a-c) show optical images of the as-deposited Ti-6Al-4V alloy from the top, side and front view, respectively. Image (d) shows a 3D view of the microstructure of the as-deposited sample.

In Figure 5 one can observe that the $\alpha$ lath size spread is quite similar for both of the samples. It is clear that for both samples, the majority of the grains are around $10 \mu \mathrm{m}$, with an average grain aspect ratio of $\sim 0.25$, which, in other words, has an equivalent thickness of $\sim 5 \mu \mathrm{m}$ for the acicular $\alpha$ phases. This is reasonable that the static air cooling rate has been reported to be less than $20^{\circ} \mathrm{C} / \mathrm{s}$ [18], which could produce an $\alpha$-plate thickness of a few microns in accordance with previous studies $[19,20]$. Gupta et al. [19] also reported that at such a cooling rate, extremely fine $\beta$-precipitates remain. Yet, there is no evidence. This also explains why there was a limited $\beta$-phase region observed in our materials. Despite the same grain morphology, the analysis of grain average misorientation (GAM) suggests that the GAM value increases after heat treatment in the sample, as shown in Figure 4c,d. It can be seen that Figure $4 \mathrm{~d}$ demonstrates a higher GAM in comparison to Figure 4c. The result suggests that higher strain or internal stress or higher dislocation density presents in the heat-treated sample in comparison to the as-deposited one. This is very confusing as normally the additive manufactured alloys show much higher internal stress than the annealed ones, which therefore accounts for the cracking that occurs occasionally during 3D 
printing. The contrary result revealed here is still unclear and deserves further investigation. On the other hand, although the underlying mechanism of yielding higher GAM values in the heat-treated sample is unknown, its effect on the compressive strength was studied under dynamic loading.
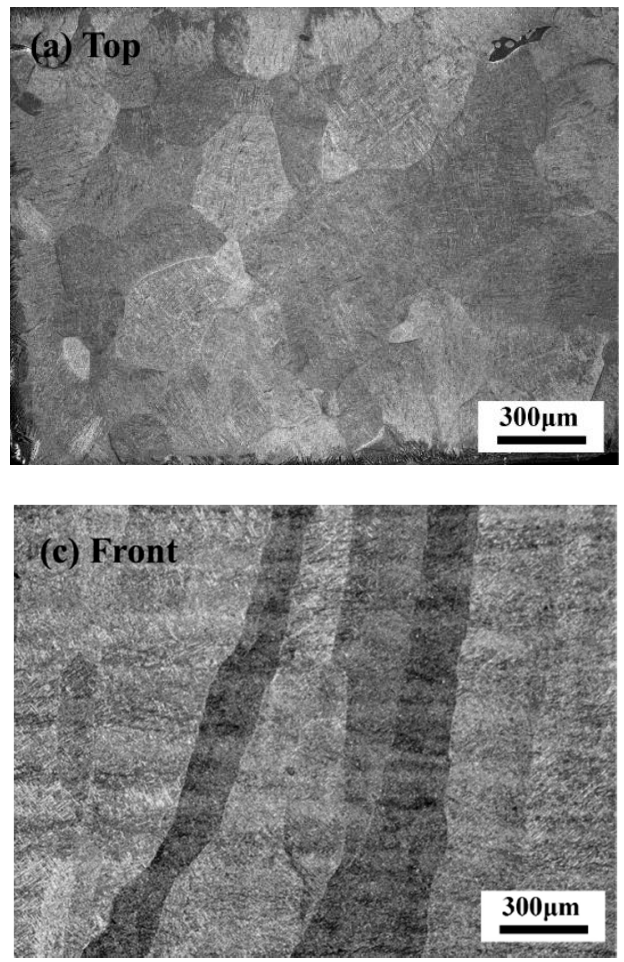

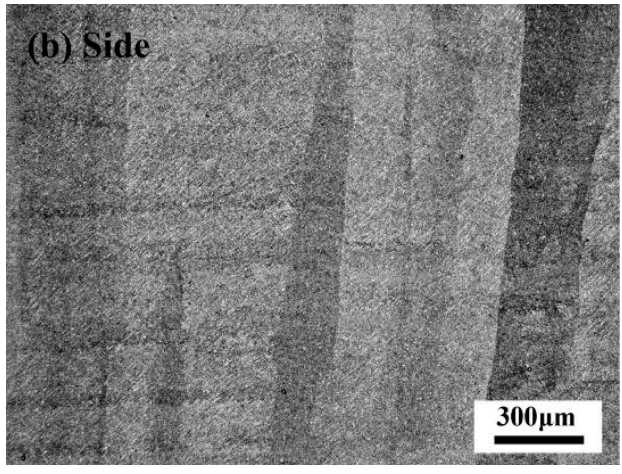

(d) 3D view

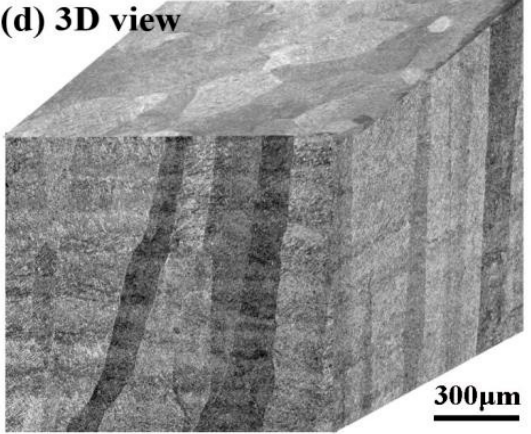

Figure 3. (a-c) show optical images of the heat-treated Ti-6Al-4V alloy from the top, side and front view, respectively. Image (d) shows a 3D view of the microstructure of the heat-treated sample.

The mechanical testing results are shown in Figure 6. In order to contrast the reliability of the results, the representative parameters directly originating from the experimental results were chosen. In addition, the results of each condition have high repeatability. It can be seen that heat treatment had a great influence on the dynamic behavior of the samples. First, in all cases, the heat-treated sample exhibited a higher compressive strength than the as-deposited one. This is in accordance with the microstructural results that the heat-treated sample has a higher internal stress than the as-deposited sample, while their grain size and morphology are, however, quite similar. Second, the as-deposited sample exhibited isotropic behavior along the $\mathrm{L}$ and $\mathrm{T}$ directions at both loading rates, while on the other hand the heat-treated sample exhibited anisotropic behavior instead, i.e., the compressive strengths along the $\mathrm{L}$ direction became visibly higher than those along the $\mathrm{T}$ direction after heat treatment. Using the true stress-strain curves, we could also estimate the strength discrepancy between the $\mathrm{T}$ and $\mathrm{L}$ loading directions, which was $\sim 50 \mathrm{MPa}$ at $500 \mathrm{~s}^{-1}$ and $\sim 130 \mathrm{MPa}$ at $3000 \mathrm{~s}^{-1}$. Considering the loading rates, the values of strain rate sensitivity (SRS) at an offset strain of $3 \%$ were calculated for both samples. For the original sample, the value was estimated to be around 0.051 , while for the heat-treated sample, the values were about 0.013 and 0.029 for the $\mathrm{T}$ and $\mathrm{L}$ directions, respectively. This suggests that the rate sensitivity of the material reduces after heat treatment. Previous studies proved that for $\mathrm{Ti}$ alloys, the SRS value decreases with increasing plastic strain [21]. Considering the higher GAM values observed in the heat-treated sample than in the as-deposited sample, the reduced SRS values are reasonable. Yet, the anisotropic behavior induced by heat treatment still needs further investigation. 

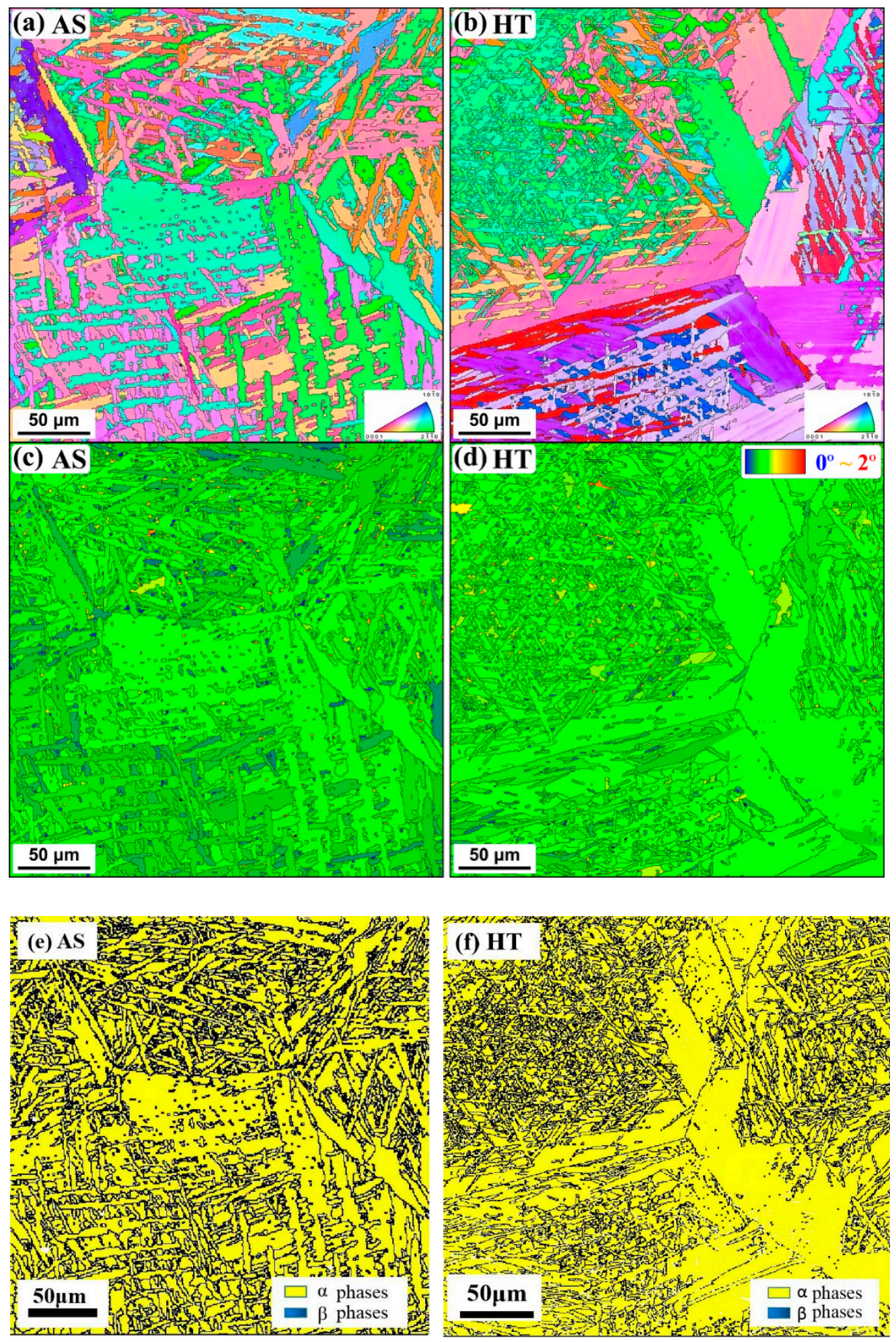

Figure 4. Microstructure of the as-deposited (AS) (a) and heat-treated (HT) (b) LAM Ti-6Al-4V alloy (SEM). Grain average misorientation (GAM) maps for (c) as-deposited and (d) heat-treated samples. Phase distribution maps for (e) as-deposited and (f) heat-treated samples. 


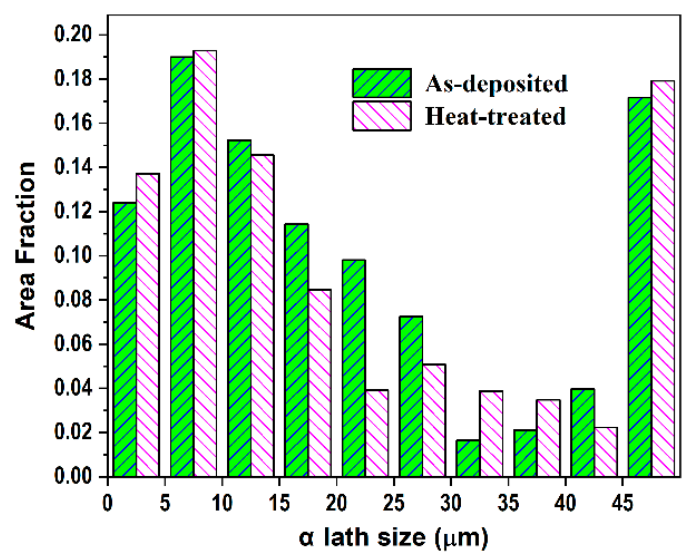

(a)

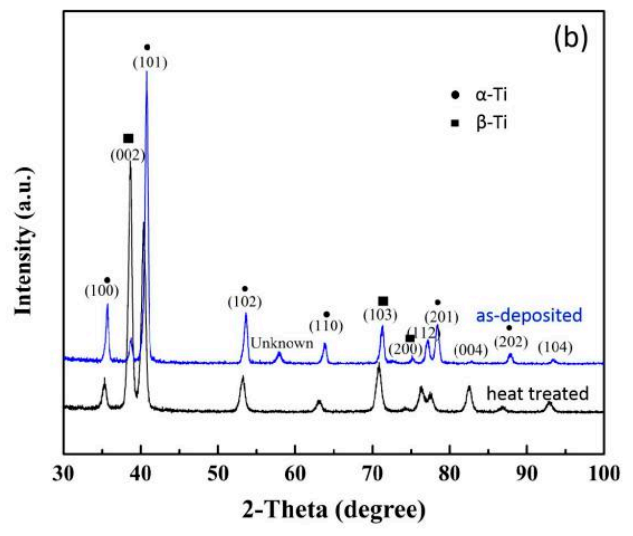

(b)

Figure 5. A histogram of the $\alpha$ lath size distribution (a) and XRD diffraction pattern (b) for the as-deposited and heat-treated samples.
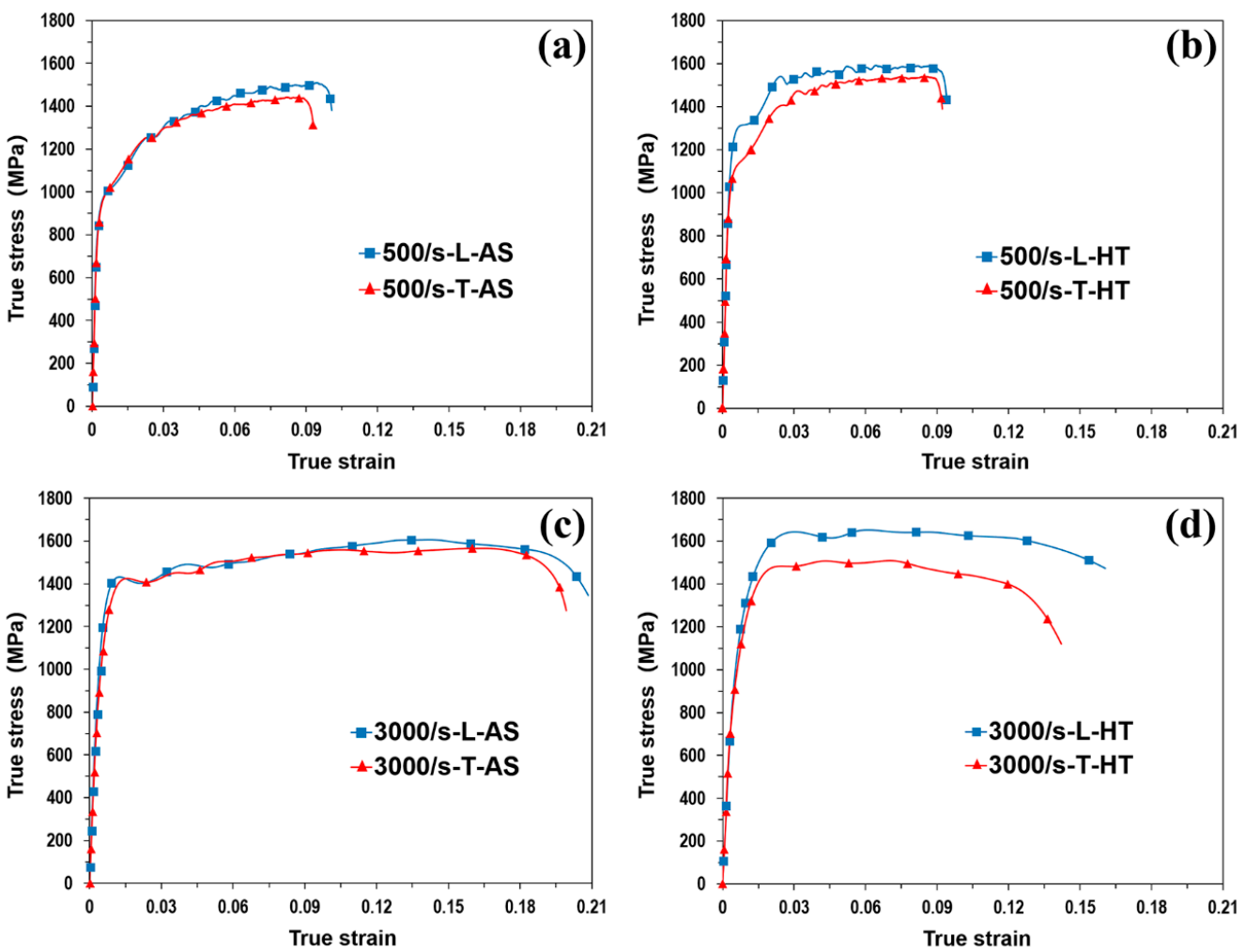

Figure 6. The dynamic true stress-true strain curves for the as-deposited and heat-treated samples, where $\mathrm{L}$ (along the direction of grain growth) and $\mathrm{T}$ (perpendicular to the direction of grain growth) indicate the direction. $(\mathbf{a}, \mathbf{c})$ indicate the strain rate is $500 / \mathrm{s}, 3000 / \mathrm{s}$ for the as-deposited, respectively. (b,d) indicate the strain rate is 500/s, 3000/s for the heat-treated, respectively.

\section{Conclusions}

In this work, the heat treatment effect on the dynamic compressive behavior of additively manufactured Ti-6Al-4V alloy was studied, and the following conclusions were obtained.

(1) The grain structure was similar before and after heat treatment; however, higher internal stress was induced in the heat-treated sample. 
(2) The dynamic compressive strength was increased by the heat treatment process for the 3D-printed material, accompanying a change of the strength from isotropic to anisotropic.

(3) Both the as-deposited and the heat-treated samples exhibited their compressive strengths positively sensitive to the loading rate, while the heat treatment reduced the strain rate sensitivity.

Author Contributions: Conceptualization, S.Z. and J.S.; methodology and investigation, S.Z., T.S. and J.Y.; formal analysis, S.Z., Y.W. and T.S.; data curation, S.Z., Y.W.; writing—original draft preparation, S.Z. and Y.W.; writing - review and editing, J.S.; supervision and project administration, Y.L. and J.S.; funding acquisition, Y.L. and J.S.; resources, X.L. and W.H. All authors have read and agreed to the published version of the manuscript.

Funding: This work was supported by the National Natural Science Foundation of China (grant No. 11502215) and the Fundamental Research Funds for the Central Universities (grant No. G2015KY0801).

Institutional Review Board Statement: Not applicable.

Informed Consent Statement: Not applicable.

Data Availability Statement: The data presented in this study are available on request from the corresponding author. The data are not publicly available due to privacy and technical patents.

Acknowledgments: In this section you can acknowledge any support given which is not covered by the author contribution or funding sections. This may include administrative and technical support, or donations in kind (e.g., materials used for experiments).

Conflicts of Interest: The authors declare no conflict of interest.

\section{References}

1. Gu, D.; Meiners, W.; Wissenbach, K.; Poprawe, R. Laser additive manufacturing of metallic components: Materials, processes and mechanisms. Int. Mater. Rev. 2013, 57, 133-164. [CrossRef]

2. Frazier, W.E. Metal Additive Manufacturing: A Review. J. Mater. Eng. Perform. 2014, 23, 1917-1928. [CrossRef]

3. Debroy, T.; Wei, H.; Zuback, J.; Mukherjee, T.; Elmer, J.; Milewski, J.; Beese, A.; Wilson-Heid, A.; De, A.; Zhang, W. Additive manufacturing of metallic components-Process, structure and properties. Prog. Mater. Sci. 2018, 92, 112-224. [CrossRef]

4. Shuangyin, Z.; Xin, L.; Jing, C.; Weidong, H. Influence of Heat Treatment on the Microstructure and Properties of Ti-6Al-4V Titanium Alloy by Laser Rapid Forming. Rare Metal Mater. Eng. 2007, 36, 1263-1266.

5. Verleysen, P.; Peirs, J. Quasi-static and high strain rate fracture behaviour of Ti6Al4V. Int. J. Impact Eng. 2017, 108, 370-388. [CrossRef]

6. Ran, C.; Chen, P.; Li, L.; Zhang, W.; Liu, Y.; Zhang, X. High-strain-rate plastic deformation and fracture behaviour of Ti-5Al-5Mo5V-1Cr-1Fe titanium alloy at room temperature. Mech. Mater. 2018, 116, 3-10. [CrossRef]

7. Kuang, L.; Chen, Z.; Jiang, Y.; Wang, Z.; Wang, R.; Liu, C. Adiabatic shear behaviors in rolled and annealed pure titanium subjected to dynamic impact loading. Mater. Sci. Eng. A 2017, 685, 95-106. [CrossRef]

8. Ahmed, M.; Wexler, D.; Casillas, G.; Savvakin, D.G.; Pereloma, E. Strain rate dependence of deformation-induced transformation and twinning in a metastable titanium alloy. Acta Mater. 2016, 104, 190-200. [CrossRef]

9. Ahn, K.; Huh, H.; Yoon, J. Rate-dependent hardening model for pure titanium considering the effect of deformation twinning. Int. J. Mech. Sci. 2015, 98, 80-92. [CrossRef]

10. Li, B.; Joshi, S.P.; Almagri, O.; Ma, Q.; Ramesh, K.; Mukai, T. Rate-dependent hardening due to twinning in an ultrafine-grained magnesium alloy. Acta Mater. 2012, 60, 1818-1826. [CrossRef]

11. Capolungo, L.; Marshall, P.; McCabe, R.; Beyerlein, I.J.; Tomé, C. Nucleation and growth of twins in Zr: A statistical study. Acta Mater. 2009, 57, 6047-6056. [CrossRef]

12. Chen, B.; Moon, S.; Yao, X.; Bi, G.; Shen, J.; Umeda, J.; Kondoh, K. Strength and strain hardening of a selective laser melted AlSi10Mg alloy. Scr. Mater. 2017, 141, 45-49. [CrossRef]

13. Zhang, Q.; Chen, J.; Zhao, Z.; Tan, H.; Lin, X.; Huang, W. Microstructure and anisotropic tensile behavior of laser additive manufactured TC21 titanium alloy. Mater. Sci. Eng. A 2016, 673, 204-212. [CrossRef]

14. Zhang, L.-C.; Attar, H.; Calin, M.; Eckert, J. Review on manufacture by selective laser melting and properties of titanium based materials for biomedical applications. Mater. Technol. 2016, 31, 66-76. [CrossRef]

15. Xu, W.; Brandt, M.S.; Sun, S.; Elambasseril, J.; Liu, Q.; Latham, K.; Xia, K.; Qian, M. Additive manufacturing of strong and ductile Ti-6Al-4V by selective laser melting via in situ martensite decomposition. Acta Mater. 2015, 85, 74-84. [CrossRef] 
16. Simonelli, M.; Tse, Y.Y.; Tuck, C. Microstructure of Ti-6Al-4V produced by selective laser melting. In Proceedings of the Electron Microscopy and Analysis Group Conference 2011, Birmingham, UK, 6-9 September 2011; Moebus, G., Walther, T., Brydson, R., Ozkaya, D., MacLaren, I., Donnelly, S., Nellist, P., Li, Z., Baker, R., Chiu, Y.L., Eds.; Iop Publishing Ltd.: Bristol, UK, 2012.

17. Zherebtsov, S.V.; Kudryavtsev, E.A.; Salishchev, G.A.; Straumal, B.B.; Semiatin, S.L. Microstructure evolution and mechanical behavior of ultrafine Tie6Ale4V during low-temperature superplastic deformation. Acta Mater. 2016, 121, 152-163. [CrossRef]

18. Xu, Z.; Zhang, Y. Quench rates in air, water, and liquid nitrogen, and inference of temperature in volcanic eruption columns. Earth Planet Sci. Lett. 2002, 200, 315-330. [CrossRef]

19. Gupta, A.; Khatirkar, R.K.; Kumar, A.; Parihar, M.S. Investigations on the effect of heating temperature and cooling rate on evolution of microstructure in an $\alpha+\beta$ titanium alloy. J. Mater. Res. 2018, 33, 946-957. [CrossRef]

20. Shaikh, A.; Kumar, S.; Dawari, A.; Kirwai, S.; Patil, A.; Singh, R. Effect of Temperature and Cooling Rates on the $\alpha+\beta$ Morphology of Ti-6Al-4V Alloy. Procedia Struct. Integr. 2019, 14, 782-789. [CrossRef]

21. Shen, J.; Chen, B.; Umeda, J.; Zhang, J.; Li, Y.; Kondoh, K. Rate sensitivity and work-hardening behavior of an advanced Ti-Al-N alloy under uniaxial tensile loading. Mater. Sci. Eng. A 2019, 744, 630-637. [CrossRef] 